\title{
A vueltas con el control de convencionalidad: avances y retrocesos de la aplicación de la norma internacional en el ordenamiento jurídico laboral español
}

\author{
Back with the control of conventionality: advances \\ and settlements of the application of the international \\ standard in the Spanish labor legal order
}

\author{
Miguel Ángel Garrido Palacios* \\ Profesor Asociado de Derecho del Trabajo \\ Universidad Complutense de Madrid \\ ORCID ID: 0000-0003-2093-1286
}

Recibido: 22/12/2020

Aceptado: 15/1/2021

doi: https://doi.org/10.20318/labos.2021.6219

Resumen: $\quad$ El debate sobre la vigencia del control de convencionalidad para asegurar los estándares más elevados de derechos desde la norma internacional se encuentra de plena actualidad en nuestro ordenamiento jurídico. Desde la Covid-19 se detecta una mayor familiaridad en el recurso a normas tales como el Convenio 158 de la OIT y la Carta Social Europea para la resolución de los litigios internos, tanto en el ejercicio del control de convencionalidad como en su rechazo. El objeto de este artículo es actualizar los elementos jurídicos y legales que avalan al control de convencionalidad, pero al mismo tiempo reflexionar sobre las cautelas, lagunas y posibles usos extensivos que se extralimitarían de su contenido y esencia. Sin duda, el debate en estos términos puede posibilitar un uso más adecuado y armónico entre el Derecho internacional y el Derecho interno.

Palabras clave: control de convencionalidad, jurisprudencia, Covid-19, Convenio 158 OIT, Carta Social Europea.

Abstract: $\quad$ The debate on the validity of conventionality control to ensure the highest standards of rights from the international norm is fully topical in our legal system. Since Covid-19, a greater familiarity has been detected in the use of standards such as ILO Convention 158 and the European Social Charter for the resolution of internal disputes, both in the exercise of conventionality control and in its rejection. The purpose of this article is to update the legal and legal elements that support the conventionality control, but at the same time to reflect on the precautions, loopholes and possible extensive uses that would exceed their 
content and essence. Undoubtedly, the debate in these terms can enable a more adequate and harmonious use between international law and domestic law.

Keywords: control of conventionality, jurisprudence, Covid-19, ILO Convention 158, European Social Charter.

\section{Planteamiento introductorio}

El interés sobre el Derecho internacional del trabajo va en aumento entre la doctrina judicial y académica ${ }^{1}$. El debate se centra en la utilidad de la norma internacional del trabajo, a través del control de convencionalidad, como herramienta jurídica hábil para recuperar elementos tuitivos que se han ido perdiendo con las sucesivas reformas laborales, en particular la de 2012.

Si bien la cuestión del control de convencionalidad data de unos pocos años atrás en nuestro ordenamiento, el Derecho internacional fue clave para la configuración de nuestro modelo de relaciones laborales democrático. El objeto de este artículo es situar los elementos legales y doctrinales que sirven para realizar la protección multinivel de derechos desde el marco internacional. No obstante lo anterior, pese a los considerables avances del control que se plasmarán en este estudio, la controversia jurídica sigue abierta con defensores y detractores del control de convencionalidad.

Las primeras resoluciones judiciales que abordaron el novedoso mecanismo exteriorizaron un conocimiento limitado de la materia, probablemente por su innecesario uso del que se partía históricamente, al ser más elevado el marco de protección nacional que el internacional. Esta primera etapa, parece superada puesto que el debate en la jurisprudencia plantea un mayor conocimiento y rigor del control de convencionalidad.

También se asiste con preocupación a un uso del control de convencionalidad extensivo o en ocasiones polémico que puede dar lugar a desvirtuar la propia figura del mecanismo. Este se reserva para los supuestos excepcionales en que nuestro ordenamiento no sea capaz de dar una solución jurídica para el respeto de los estándares de ámbito internacional lo que necesariamente debe dar lugar a la inaplicación de la norma interna. En este sentido, este artículo reflexiona sobre elementos de naturaleza constitucional, de colisión con el Derecho comunitario o del alcance de las resoluciones de los órganos de control, que sin duda han de ser tenidos en cuenta para situar correctamente el alcance del control de convencionalidad.

Antes de adentrarme en el análisis del estado de la cuestión es menester acotar que textos se integran en el contenido del Derecho internacional del trabajo, para recoger el contenido de este que es susceptible de ser tratado desde el prisma del control de convencionalidad.

\section{El concepto de Derecho internacional del trabajo y su importancia en el derecho interno}

Se parte de un concepto del Derecho internacional del trabajo, ciertamente desconocido por nuestros operadores jurídicos aunque esto se va revirtiendo poco a poco. Algunos autores lo caracterizan como un régimen jurídico ${ }^{2}$. Otros sectores autorizados de la doctrina ${ }^{3}$ ubican al Derecho interna-

\footnotetext{
${ }^{1}$ GOERLICH PESET, José María, 2021. (Re)descubriendo el control de convencionalidad: ‘activismo o autocontención judicial). En: https://e-revistas.uc3m.es/index.php/LABOS/index. Disponible en https://doi.org/10.20318/labos.2021.6044 [consulta: 31 de marzo 2021].

${ }^{2}$ BONET PÉREZ, Jordi. Las relaciones laborales como objeto de reglamentación jurídica internacional: origen y evolución, En: Bonet Pérez, J. y Olesti Rayo, A. (dirs.) Nociones básicas sobre el régimen jurídico internacional del trabajo, Barcelona, Huygens, 2010 , p. 34.

${ }^{3}$ En este sentido dedica su obra monográfica SERVAIS, Jean Michel. Derecho Internacional del Trabajo. Buenos Aires: Editorial Heliasta, 2011.
} 
cional del trabajo como disciplina autónoma que forma parte del Derecho internacional público y la propia Organización Internacional del Trabajo lo emplea en dichos términos ${ }^{4}$. Existen una serie de elementos históricos que refuerzan y justifican esta idea y que enumero a continuación.

Remontándome al siglo XIX el Derecho internacional del trabajo se vertebraría por la interacción de una serie de factores: el interés de los Estados en disciplinar al mercado en condiciones de competencia; la incorporación de unas condiciones mínimas dignas fundamentalmente de higiene y salubridad, la limitación de las jornadas de trabajo extenuantes y el trabajo infantil entre otras cuestiones. Todo este recorrido con sus contradicciones, luces y sombras propias de ese periodo histórico lleva al nacimiento de la Organización Internacional del Trabajo y demuestra que la norma internacional hizo acto de presencia en los inicios de la conformación del Derecho del Trabajo.

La consolidación del Derecho internacional del trabajo se produce con el marco jurídico que se plasma tras la finalización de la II Guerra Mundial y donde la Organización Internacional del Trabajo tiene un papel protagónico. Con la Declaración de Filadelfia y la aprobación de los grandes convenios, ocupa un lugar central en la esfera internacional llegando a considerarse "Código Internacional del Trabajo" al compendio de convenios y recomendaciones que se han ido produciendo a lo largo del tiempo. Sin embargo, no se pueden olvidar las críticas vertidas a la organización en todo este tiempo y que se pueden sintetizar en: su carácter reformista para frenar los efectos de la Revolución Rusa ${ }^{6}$, el tratamiento diferencial para los trabajadores de las metrópolis y el de los indígenas en las colonias ${ }^{7}$, o su incapacidad para adaptarse a los tiempos de la globalización y la Lex Mercatoria, etc.

El otro pilar del Derecho internacional del trabajo es la Carta Social Europea que procede del Consejo de Europa. Pese a que el texto fuerte de esta organización es el Convenio Europeo de Derechos Humanos, la Carta es un instrumento al alza ante las medidas de austeridad aplicadas en Europa por los efectos de la crisis financiera de 2008. Se ha llegado a afirmar que con la interpretación que hace de la misma el Comité Europeo de Derechos Sociales se constituye en el último bastión de los derechos sociales en Europa?.

Con estas cuestiones previas, se podría precisar que el Derecho internacional del trabajo abarca todas las normas de fuente pública que reconocen derechos laborales o dicho de otra forma, las normas supranacionales que contribuyen a la institucionalización y regulación de las relaciones la-

\footnotetext{
${ }^{4}$ Así se emplea la OIT entendiendo que sus Convenios y Recomendaciones suponen una fuente de derecho internacional. Disponible en https://www.ilo.org/inform/online-information-resources/research-guides/labour-law/lang--es/index.htm [consulta: 31 de marzo 2021].

${ }^{5}$ VALTICOS, Nicolas, Derecho Internacional del Trabajo. Madrid, Tecnos, 1977, p. 105.

${ }^{6}$ CEBREIROS ÁLVAREZ, Eduardo. Estructura orgánica y funcionamiento de la Organización Internacional del Trabajo en su etapa inicial (1919-1939). En: CHAMOCHO CANTUDO, Miguel Ángel, RAMOS VÁZQUEZ, Isabel y ESPUNY TOMÁS, María Jesús (coords.). La Organización Internacional del Trabajo. Cien años de protección jurídica internacional de la clase obrera (19192019), Valencia: Tirant Lo Blanch, 2019, pp. 75-113.

${ }^{7}$ Sobre este punto cabe remitirse al trabajo de investigación de BARRAGÁN ROMANO, Rossana. La geografía diferencial de los derechos. Entre la regulación del trabajo forzado en los países coloniales y la disociación entre trabajadores e indígenas en los Andes (1920-1954). En Caruso L. y Stagnaro, A. (Coords.). Una historia regional de la OIT. Aportes sobre regulación y legislación del trabajo latinoamericano, La Plata, 2017, Universidad Nacional de La Plata. Facultad de Humanidades y Ciencias de la Educación. (Estudios/Investigaciones; 62), pp. 25-63. Disponible en http://libros. fahce.unlp.edu.ar/index.php/libros/catalog/book/93

Igualmente, RODRIGUEZ-PIŃERO ROYO, Luis, pone el acento en que estas políticas derivaban de la doctrina de la tutela que era expresión del imperialismo europeo y donde predominaba la visión de jerarquía de razas y culturas siendo el elemento por el que se trataba de justificar el trato desigual el de carencia de "civilización". Véase su artículo "La OIT y los pueblos indígenas en el derecho internacional del colonialismo al multiculturalismo”, Trace, México, Cemca 46, 2004, pp. 59-81.

${ }^{8}$ GUAMÁN HERNÁNDEZ, Adoración y NOGUERA FERNÁNDEZ, Albert, Derechos sociales, integración económica y medidas de austeridad. La UE contra el constitucionalismo social. Albacete, Bomarzo, 2014.

${ }^{9}$ JIMENA QUESADA, Luis. Introducción: sostenibilidad y efectividad de los derechos sociales, incluso y sobre todo en tiempos de crisis, En: ALFONSO MELLADO, Carlos Luis., JIMENA QUESADA, Luis y SALCEDO BELTRÁN, Carmen, La jurisprudencia del Comité Europeo de Derechos Sociales frente a la crisis económica, Albacete: Bomarzo, 2014, pp. 13-48.
} 
borales ${ }^{10}$. En tal sentido, y con la intención de ser expositivo, comprendería como textos principales a los Pactos internacionales de Naciones Unidas, los convenios de la OIT, el Convenio Europeo de Derechos Humanos y la Carta Social Europea.

Una vez determinado el ámbito normativo del Derecho internacional del trabajo se puede asistir a la conformación de su conglomerado teórico.

\section{Los orígenes del control de convencionalidad}

El control de convencionalidad es una herramienta jurídica que permite preservar el nivel de protección más alto de derechos desde la norma internacional cuando la norma interna contradice abiertamente lo pautado por aquella. Es la selección de la norma aplicable por el juez ordinario predeterminado por la ley al margen del control de constitucionalidad de la norma que es una cuestión distinta.

Su armazón teórica tiene su origen en el Sistema Interamericano de Derechos Humanos, cuya Corte Interamericana ha ido vertebrando el concepto a través de la evolución de su jurisprudencia para asegurar los estándares internacionales. El panorama jurídico interamericano nos trae dos enseñanzas positivas para aprehender en nuestra arquitectura jurídica:

La primera cuestión es el desarrollo jurisprudencial que agregó el control de convencionalidad como fundamento del cumplimiento de la Convención Americana de Derechos Humanos. Su consolidación fue paulatina ya que se partía de la posición particular de un juez ${ }^{11}$ hasta conseguir que se asentara en las resoluciones de la Corte Interamericana.

La segunda cuestión es la trascendencia del diálogo ${ }^{12}$ en clara conexión con la primera. Ha sido el vehículo que ha posibilitado asentar la herramienta jurídica para proteger los estándares más elevados de derechos humanos de conformidad con el marco internacional. Pero para ello es necesario acotar en que consiste el diálogo judicial, no debiendo confundirse con la mera cita de la jurisprudencia de otros tribunales. Sería el debate de ideas o razonamientos en la perspectiva de la resolución del conflicto ${ }^{13}$. Desde otro punto de vista, el ejercicio del control de convencionalidad refuerza el diálogo ${ }^{14}$ puesto que obliga al juez nacional a razonar conforme a la norma internacional y en sintonía con los órganos internacionales, como muestra la experiencia latinoamericana.

$\mathrm{Al}$ margen del diálogo y de la construcción jurisprudencial se trata del deber de adecuación del derecho interno al derecho internacional tal y como se desprende de los artículos 26 y 27 de la Convención de Viena ${ }^{15}$. Más adelante se aborda la recepción de la norma internacional desde la óptica de nuestra Constitución.

${ }^{10}$ GARCÍA MURCIA, Joaquín. La legislación laboral internacional: mandato y función de la organización internacional del trabajo. Documentación Laboral. Revista de la Asociación Española de Derecho del Trabajo y de la Seguridad Social. Madrid, Cinca, 1,116, 2019, pp. 9-16.

${ }^{11}$ SAGÜES, Néstor Pedro, el "control de convencionalidad” en el sistema interamericano, y sus anticipos en el ámbito de los derechos económico-sociales. Concordancias y diferencias con el sistema europeo. En: FERRER MAC GREGOR, Eduardo y HERRERA GARCÍA, Alfonso (coords.). Diálogo jurisprudencial en derechos humanos entre tribunales constitucionales y cortes internacionales, México: Tirant Lo Blanch, 2013, pp. 993-1030.

${ }^{12}$ DE FIGUEIREDO CALDAS, Roberto. Estructura y funcionamiento del sistema interamericano de derechos humanos: sus herramientas para un efectivo diálogo judicial. En: SAIZ ARNAIZ, Alejandro (dir.), SOLANES MULLOR, Joan y ROA ROA, Jorge Ernesto (coords.), Diálogos judiciales en el sistema interamericano de derechos humanos, Valencia: Tirant Lo Blanch, 2017, pp. 45-62.

${ }^{13}$ DIAZ CREGO, María, Diálogo judicial. Eunomía, Revista de la Cultura de la Legalidad. Getafe (Madrid), no 9, octubre 2015-marzo 2016, 2015, pp. 289-299.

${ }^{14}$ GARCÍA RAMÍREZ, Sergio. El control judicial interno de convencionalidad. En IUS: Revista del Instituto de Ciencias Jurídicas de Puebla. México, Vol.28, julio-diciembre, 2011, pp. 129.

${ }^{15}$ TORRES ZUNIGA, Natalia. Control de normas constitucionales por la Corte Interamericana de derechos humanos: subsidiariedad, deferencia e impacto en la teoría del cambio constitucional. En: SAIZ ARNAIZ, Alejandro (dir.), SOLANES MULLOR, 
El panorama interamericano sobre el control de convencionalidad sigue en constante desarrollo. La sentencia pionera se produjo en el caso Almonacid Arellano y otros contra Chile ${ }^{16}$ en el que se discutió el decreto de amnistía del Gobierno del General Pinochet que amparó sus crímenes, entre otros el del señor Almonacid. Para la Corte, el control de convencionalidad ha de ser ejercido por el poder judicial cuando afecta a la Convención Americana de Derechos Humanos, otorgando la protección establecida en la misma cuando las leyes nacionales la niegan. El siguiente matiz que se añade es que el control de convencionalidad ha de ser ejercido de oficio por el Poder Judicial ${ }^{17}$. Más adelante, se precisa que debe abarcar hasta la propia Constitución rectora del ordenamiento de cada Estado ${ }^{18}$. Completando los elementos del control de convencionalidad no solo implica la inaplicación de la norma interna sino de interpretación de las normas nacionales conforme ${ }^{19}$ a la Convención Americana de Derechos Humanos ${ }^{20}$. Como se puede ver su extensión progresiva conecta con la protección multinivel de los derechos humanos.

El vigor del Sistema Interamericano de Derechos Humanos se mantiene en la actualidad, lo que demuestra la reciente sentencia de la Corte Interamericana, caso Empleados de la Fábrica de Fuegos en Santo Antônio y sus familiares vs. Brasil ${ }^{21}$. En este asunto, la Corte comprueba que Brasil no tomó las medidas adecuadas en relación con la seguridad y salud de los trabajadores, la protección de la infancia ante el trabajo infantil o las debidas garantías en el procedimiento y la tutela judicial efectiva en las distintas vías que se abrieron en el plano interno. Lo interesante es que la Corte declara violada la Convención Americana de Derechos Humanos en una serie de preceptos integrando los estándares internacionales que emanan del Comité de Derechos Económicos, Sociales y Culturales, los convenios de la OIT, los comités de Naciones Unidas, etc.

\section{El encaje del control de convencionalidad en nuestro ordenamiento jurídico}

El control de convencionalidad presenta una serie de dificultades cuando aterriza en nuestro sistema legal. Se ha venido a precisar que nuestro ordenamiento no comprende unos mecanismos procesales expresos para utilizarlo lo que incide en la renuencia del juez ordinario a su ejercicio ${ }^{22}$. Sin embargo, existen vías jurídicas solventes que emanan de la propia Constitución para asegurar los estándares internacionales por esta vía.

Como balance previo en relación con el marco comparado interamericano respecto a España, la situación aun es insatisfactoria. El estado de la cuestión en nuestra jurisprudencia muestra que

Joan y ROA ROA, Jorge Ernesto (coords.), Diálogos judiciales en el sistema interamericano de derechos humanos, Valencia: Tirant Lo Blanch, 2017. p. 90-126.

${ }^{16}$ Sentencia Corte Interamericana de Derechos Humanos de 26 de septiembre de 2006, Caso Almonacid Arellano y otros contra Chile. Disponible en https://www.corteidh.or.cr/docs/casos/articulos/seriec_154_esp.pdf [consulta: marzo 2021].

17 Sentencia Corte Interamericana de Derechos Humanos de 24 de noviembre de 2006. Caso Trabajadores Cesados del Congreso (Aguado Alfaro y otros) vs. Perú. Disponible en https://www.corteidh.or.cr/docs/casos/articulos/seriec_158_esp.pdf [consulta: marzo 2021].

${ }^{18}$ Sentencia Corte Interamericana de Derechos Humanos de 20 de diciembre de 2007, Caso Boyce y otros vs. Barbados. Disponible en http://www.corteidh.or.cr/docs/casos/articulos/seriec_169_esp.pdf [consulta: marzo 2021].

${ }^{19}$ DE FIGUEIREDO CALDAS, Roberto. 2017, op., cit., p. 56.

${ }^{20}$ Sentencia Corte Interamericana de Derechos Humanos de 23 de noviembre de 2009, Caso Radilla Pacheco vs. Estados Unidos Mexicanos. Disponible en www.corteidh.or.cr > casos > articulos > seriec_209_esp [consulta: 31 de marzo de 2021]

${ }^{21}$ Sentencia Corte Interamericana de Derechos Humanos de 15 de julio de 2020. Caso Empleados de la Fábrica de Fuegos en Santo Antônio de Jesús y sus familiares vs. Brasil. En este asunto se aborda las medidas de reparación tomadas por el Estado hacía las víctimas y sus familiares ante el incendio de la Fábrica que provocó la muerte de 60 personas entre las que se encontraban 19 niñas y un niño así como múltiples heridos. Disponible en https://www.corteidh.or.cr/docs/casos/articulos/seriec_407_esp.pdf [consulta: 31 de marzo de 2021]

22 NUEVO LÓPEZ, Pablo. Control de convencionalidad y aplicación judicial de los derechos fundamentales de la Unión Europea. Revista catalana de dret públic. Barcelona, 50, 2015, pp. 141-160. 
pese a que se están consiguiendo progresos, la situación está lejos de ser armónica con el control. Respecto al diálogo con los órganos internacionales, se observan importantes déficits puesto que más allá de la articulación de cuestiones prejudiciales con el Tribunal de Justicia de la Unión Europea, no se aprecia que esté asumido un debate abierto con los órganos principales que interpretan la norma internacional del trabajo: El Comité Europeo de los Derechos Sociales y los órganos de control de la Organización Internacional del Trabajo.

No se puede olvidar que la norma internacional interactúa en dos planos; desde el artículo 10. 2 de la Constitución española como canon hermenéutico en la interpretación de nuestros derechos fundamentales y libertades y desde el control de convencionalidad por el artículo 96 de la Constitución española.

Si bien existía un debate sobre la prelación entre la norma internacional y la ley, con posiciones de la doctrina que defendían la igualdad entre ambas ${ }^{23} \mathrm{e}$ incluso la necesidad de acudir a una cuestión de inconstitucionalidad en casos de conflicto $^{24}$ ha quedado aclarado con la aprobación de la Ley 25/2014, de 27 de noviembre, de Tratados y otros Acuerdos Internacionales que reafirma el carácter supralegal de los tratados. El artículo 31 de dicha norma vigoriza la prevalencia de la norma internacional sobre la interna ${ }^{25}$ al margen de la propia norma constitucional configurada como suprema en el ordenamiento. Asimismo el artículo 35 fija el control de convencionalidad al entender que en la interpretación de los tratados se realizará conforme a las normas de las organizaciones internacionales ${ }^{26}$. Sin embargo, en nuestro ordenamiento jurídico se observa que se encuentra huérfano de tratamiento científico ${ }^{27}$ lo que dificulta la expansión de su conocimiento e implantación. En este punto la formación jurídica internacionalista y desde los derechos humanos se muestra necesaria tal y como el Comité de Derechos Económicos, Sociales y Culturales le requirió a España ${ }^{28}$.

No obstante, la doctrina sigue dividida sobre la pertinencia del control de convencionalidad. La posición favorable al mismo postula que procede de la Carta Magna y que sirve para vigorizar las fuentes y la propia Constitución. No ejercer el control, supone situar al Estado desde el incumplimiento con el Derecho internacional ${ }^{29}$. Este sector conecta el principio de jerarquía normativa del artículo 9.3 de la Constitución en relación con el artículo 96 en la prevalencia de la norma internacional sobre la interna.

Sin embargo, otros sectores de la doctrina denuncian cierta confusión con el uso de esta técnica. Ello es así puesto que plantean que el control de convencionalidad extrapola la primacía del Derecho de la Unión Europea siendo marcos distintos. El comunitario es un orden de aplicación directa como sistema autónomo a diferencia del Derecho internacional del trabajo que proviene

\footnotetext{
${ }^{23}$ GÓMEZ SÁNCHEZ, Yolanda, Constitucionalismo multinivel: derechos fundamentales. Madrid, Sanz y Torres, 2018.

${ }^{24}$ GARCÍA-PERROTE ESCARTÍN, Ignacio. Carta de los Derechos Fundamentales de la Unión Europea, Carta Social europea y reforma laboral española. Trabajo y Derecho. Las Rozas (Madrid), 15, 2016, pp. 18-44.

${ }^{25}$ DIEZ-HOCHLEITNER RODRÍGUEZ, Javier, Artículo 31. Prevalencia de los tratados, En: ANDRÉS SÁENZ DE SANTAMARÍA Paz Andrés, DÍEZ-HOCHLEITNER RODRÍGUEZ, Javier y MARTÍN Y PÉREZ DE NANCLARES, José (dirs.), Comentarios a la ley de tratados y otros acuerdos internacionales, Cizur Menor (Navarra), Aranzadi, 2015, pp. 575-587.

${ }^{26}$ PRECIADO DOMENECH, Carlos Hugo, Interpretación de los Derechos Humanos y los Derechos Fundamentales. Cizur Menor (Navarra), Aranzadi, 2016.

${ }^{27}$ JIMENA QUESADA, Luis, Jurisdicción nacional y control de convencionalidad. A propósito del diálogo judicial global y de la tutela multinivel de derechos. Cizur Menor (Navarra), Aranzadi, 2013, p. 25.

${ }^{28}$ Comité de Derechos Económicos, Sociales y Culturales. Observaciones finales sobre el sexto informe periódico de España (E/C.12/ESP/CO/6, 25 de abril de 2018). Disponible en https://tbinternet.ohchr.org/_layouts/15/treatybodyexternal/Download. aspx?symbolno=E\%2fC.12\%2fESP\%2fCO\%2f6\&Lang=en [consulta: 31 de marzo de 2021].

${ }^{29}$ Defienden estas posiciones autores como JIMENA QUESADA, Luis, 2013, op.cit, SALCEDO BELTRÁN, Carmen, De nuevo sobre el periodo de prueba tras la doctrina del Tribunal Constitucional: el necesario respeto a las normas internacionales (a propósito de la SJS n. 3 de Barcelona de 5 de noviembre de 2014). Revista de Derecho Social. Albacete, Bomarzo, 68, 2014, pp. 143160 o GUAMÁN HERNÁNDEZ, Adoración. Los desencuentros entre el Tribunal Constitucional y las normas internacionales del trabajo a propósito de la ley 3/2012 (sobre el derecho al trabajo y las SSTC 119/2014 y 8/2015. Revista de Derecho Social, Albacete, Bomarzo, no 70, 2015, pp. 149-172, entre otros.
} 
de los tratados y se integran en nuestro ordenamiento jurídico. En esta crítica se aconseja agotar la interpretación conforme más que activar la inaplicación de la norma interna. Se aboga en todo caso por ejercer el control concentrado desde el Tribunal Constitucional por seguridad jurídica que dispersarlo entre los organos judiciales ${ }^{30}$. A esto último se ha venido a discrepar, puesto que el control difuso asegura un mejor uso del control de convencionalidad que su concentración en un único órgano por los hipotéticos peligros de manipulación ${ }^{31}$.

Del debate presentado es pertinente resaltar que el propio control de convencionalidad tiene un perfil subsidiario y complementario. Su intervención se reserva a los casos explícitos en que no es posible salvar la norma interna con una interpretación acorde a la norma internacional. Es el caso del ya extinto contrato de apoyo a los emprendedores donde su regulación confrontaba con el artículo 4.4 de la Carta Social Europea que impone el derecho al preaviso razonable o la causalidad en la extinción del contrato de trabajo que mandata el artículo 4 del Convenio 158 de la Organización Internacional del Trabajo.

Se da la paradoja que el mecanismo del artículo 10.2 de la Constitución española ha funcionado razonablemente bien y en cambio la utilización del artículo 96 de nuestra norma suprema ha sido prácticamente inédita. No por casualidad, se ha llegado a defender que la interpretación del texto constitucional se encuentra en un proceso de internacionalización ${ }^{32}$ o que el canon hermenéutico sirve como complemento y enriquecimiento del mecanismo del artículo 96 de la Constitución ${ }^{33}$. Esto explicita que el control de constitucionalidad respecto al marco internacional se encuentra perfectamente engrasado en contraste con el control de convencionalidad, como se verá a continuación.

El problema radica en el papel del Tribunal Constitucional sobre su interpretación de la fuente internacional en sus sentencias 119/2014 y 8/2015. Elementos centrales de la reforma laboral de 2012 confrontaban con criterios consolidados de fuente internacional. En tal sentido, el Tribunal Constitucional ha venido a desechar el estándar internacional. Primero, planteando que la Comisión de Expertos en Aplicación de Convenios y Recomendaciones se manifiesta con que el contrato de apoyo a los emprendedores no es contrario al Convenio 158 de la Organización Internacional del Trabajo cuando el órgano se pronunció en el sentido que no tenía elementos suficientes para decantarse en un sentido o en otro. En cambio se omite que ese órgano de la Organización Internacional del Trabajo planteó que una regulación que promueve una extinción generalizada sin causa era contraria a dicha norma internacional ${ }^{34}$. Segundo, obviando posiciones firmes sobre arbitraje, libertad sindical y negociación colectiva de la Comisión de Expertos en Aplicación de Convenios y Recomendaciones y del Comité de Libertad Sindical ${ }^{35}$. Tercero, en la segunda sentencia del Tribunal Constitucional, el Comité Europeo de Derechos Sociales ya se había pronunciado declarando el contrato de apoyo a los emprendedores contrario a la Carta Social Europea ${ }^{36}$. Ante esta devalua-

\footnotetext{
${ }^{30}$ Representa esta posición CANOSA USERA, Raúl, El control de convencionalidad. Cizur Menor, Aranzadi, 2015.

${ }^{31}$ PRECIADO DOMENECH, Carlos Hugo, Teoría general de los derechos fundamentales en el contrato de trabajo. Cizur Menor (Navarra), Aranzadi, 2018.

${ }^{32}$ PÉREZ DE LOS COBOS ORIHUEL, Francisco. 2016. El diálogo entre el Tribunal Europeo de Derechos Humanos y el Tribunal Constitucional: una relación fructifera. Ponencia presentada en la Conferencia Internacional: los retos y las perspectivas de la justicia constitucional contemporánea, San Petersburgo. En www.tribunalconstitucional.es.Disponible en https://www.tribunalconstitucional.es/ActividadesDocumentos/2016-05-17-00-00/Ponencia\%20del\%20Presidente\%20del\%20Tribunal\%20Constitucional.pdf [consultado: 9 de abril de 2021].

${ }^{33}$ MARTINEZ MORENO, Carolina, El marco internacional para la tutela de los derechos laborales. Lex Social: Revista Jurídica de los Derechos Sociales, 6 (1), 2016, p. 108.

${ }^{34}$ Informe de la CEACR, 2014, presentada en la 321 reunión del Consejo de Administración de la OIT de 13 de junio de 2014. Disponible en https://www.ilo.org/wcmsp5/groups/public/---ed_norm/---relconf/documents/meetingdocument/wcms_247068.pdf

${ }^{35}$ Véase los casos 2918 y 2947 resueltos por el Comité de Libertad Sindical.

${ }^{36}$ COMITÉ EUROPEO DE DERECHOS SOCIALES 2014. Conclusiones XX-3, de 5 de diciembre de 2014. Disponible en https://hudoc.esc.coe.int/eng\#\{\%22sort\%22:[\%22ESCPublicationDate\%20Descending\%22],\%22ESCDcIdentifier\%22:[\%22 XX-3/def/ESP/4/4/EN\%22]\} [consultado: 9 de abril de 2021].
} 
ción de la protección constitucional, la doctrina científica se ha pronunciado por señalar la excesiva politización del Tribunal Constitucional, ${ }^{37}$ hasta el cuestionamiento de su posición cuando ignora o se sitúa en contra de los órganos de control de los tratados que firma España ${ }^{38}$. En definitiva, el Tribunal Constitucional al haber rechazado utilizar el canon internacional para declarar la inconstitucionalidad de la norma ha provocado que la tutela de los derechos se haya ejercido desde el juez ordinario utilizando el control de convencionalidad ${ }^{39}$.

No obstante lo anterior, el Tribunal Constitucional en su sentencia de 20 de diciembre de $2018^{40}$ ha venido a marcar un punto de inflexión a favor del control de convencionalidad. Esta resolución descarta que exista un modelo de jurisdicción universal en nuestra Constitución para al mismo tiempo explicitar la necesidad del control en cuanto al canon internacional por el juez ordinario. Como se ha puesto de relieve nunca el Tribunal Constitucional se había pronunciado de forma más abierta y expresa a favor del control de convencionalidad ${ }^{41}$. Esta sentencia ha sido criticada por sectores de la doctrina al estimar que erróneamente se extrapola el paradigma jurídico interamericano cuando este no se pronuncia por el control difuso o el concentrado y que se ha producido, al pie de esta resolución, el aumento del parámetro de control de las leyes más allá de la Constitución y el bloque de constitucionalidad desde el marco internacional ${ }^{42}$. No obstante, no se puede olvidar la experiencia positiva en la aplicación del control de convencionalidad por la Corte Interamericana de Derechos Humanos y lo preceptuado en el artículo 96 de la Constitución Española con el desarrollo dado por la Ley 25/2014, por lo que si el Tribunal Constitucional rehúsa dicho control, el mismo ha de ser cumplido por el juez ordinario. Es por ello que el control de convencionalidad vigoriza el control de constitucionalidad ya que este último siempre puede ser ejercido ante una aplicación incorrecta del control de convencionalidad por el juez ordinario o a su vez por el rechazo a ejercer el control siempre que se lesione un derecho fundamental, debiendo recordar que en nuestro modelo la tutela inmediata de los derechos fundamentales no lo ejerce el Tribunal Constitucional, lo que por otro lado sería inviable, sino que es competencia del juez ordinario que también ha de tener en cuenta al control de convencionalidad ${ }^{43}$.

\section{El alcance de las resoluciones de los órganos de control}

Otro de los argumentos que han servido para tratar de aminorar la influencia de la norma internacional ha sido caracterizar como no vinculantes las resoluciones de los órganos de control. Conviene precisar si esta posición es correcta o no. La norma internacional tiene como uno de sus rasgos la generalidad para adaptarse a las distintas realidades domésticas, lo que hace que los órganos de control con sus informes y resoluciones ajusten la norma a la realidad de cada país, lo que coadyuva a su aplicación en particular ${ }^{44}$.

\footnotetext{
${ }^{37}$ GUAMÁN HERNÁNDEZ, Adoración, Los desencuentros entre el Tribunal Constitucional y las normas internacionales del trabajo a propósito de la ley 3/2012 (sobre el derecho al trabajo y las SSTC 119/2014 y 8/2015. Revista de Derecho Social. Albacete, Bomarzo, no 70, 2015, p. 171.

${ }^{38}$ GUAMÁN HERNÁNDEZ, Adoración. 2015, op.cit., p. 159.

${ }^{39}$ FONDEVILA MARÓN, Manuel, El control de convencionalidad por los jueces y tribunales españoles: a propósito de la STC 140/2018, de 20 de diciembre. Anuario Iberoamericano de Justicia Constitucional. 23(2), 2019, pp. 439-458.

${ }^{40}$ STC 140/2018 de 20 de diciembre.

${ }^{41}$ JIMENA QUESADA, Luis. La consagración del control de convencionalidad por la jurisdicción constitucional en España y su impacto en materia de derechos sociolaborales (comentario a la STC 140/2018, de 20 de diciembre). Revista General de Derecho de Trabajo y de la Seguridad Social, 53, 2019, pp. 435-461.

${ }^{42}$ ALONSO GARCÍA, Ricardo, El control de convencionalidad: cinco interrogantes. Revista Española de Derecho Constitucional. 119, 2020, pp. 13-51.

${ }^{43}$ FONDEVILA MARÓN, Manuel. 2019, op. cit.

${ }^{44}$ GONZÀLEZ DE RIVERA I SERRA, Xavier, 2015. Conversaciones sobre la norma internacional y la norma interna: la aplicación por los órganos judiciales. XXVI Jornadas catalanas de derecho del trabajo: los derechos laborales desde la perspectiva de la teoría
} 
A mi entender la tesis de aquellos sectores de la doctrina que plantean que las resoluciones de los órganos de control de los tratados internacionales son jurisprudencia en sentido material es acertada. Si bien no es jurisprudencia en sentido estricto su interpretación ha de ser atendida por los tribunales. Ello es así por una serie de motivos: En primer lugar, porque se trata de la voz de los tratados según impone el artículo 31 del Convenio de Viena. En segundo lugar, porque así lo reproduce la Ley 25/2014 de Tratados y otros Acuerdos Internacionales en su artículo 35. En tercer lugar, puesto que aunque no sean tribunales en un sentido estricto, en tanto en cuanto sus resoluciones son reproducidas en las sentencias se incorporan como jurisprudencia en el plano interno ${ }^{45}$.

Además, las resoluciones de estos órganos gozan de una importante autoridad. Las de la Comisión de Expertos en Aplicación de Convenios y Recomendaciones y las del Comité de Libertad Sindical de la Organización Internacional del Trabajo sirvieron para acompañar y definir el proceso por la democracia en Espańa hasta la propia implantación del modelo democrático de relaciones laborales. Por su parte, el Comité Europeo de Derechos Sociales ha cobrado una mayor relevancia con las resoluciones e informes tomados al calor de la crisis financiera de 2008.

En cuanto a la situación respecto a la todavía no ratificada Carta Social Europea revisada de 1996 conviene realizar una serie de precisiones. La cuestión controvertida radica en la no ratificación por Espańa del sistema de reclamaciones colectivas que incorpora tanto dicha versión de la Carta como el protocolo anterior de 1995 , aunque esto está cerca de cambiar ${ }^{46}$. Hasta la fecha la única intervención que tiene el Comité Europeo de Derechos Sociales sobre nuestro país es desde los informes periódicos que chequea los derechos ratificados por el Estado. Aun así, las resoluciones sobre otros países que se pronuncian sobre derechos que están ratificados por Espańa si son vinculantes para nuestra jurisprudencia. Más discutible es este mismo efecto sobre la Carta Social Europea no ratificada por nuestro país, precisamente por el mismo derecho de los tratados al que nos dirigimos para defender la prevalencia del Derecho internacional sobre los contenidos si ratificados por España.

\section{La interacción del Derecho internacional del trabajo con el Derecho de la Unión Europea}

No es objeto de este artículo abordar a fondo la extensa y compleja cuestión del Derecho de la Unión Europea, no obstante conviene situar la problemática ligada a su colisión con el Derecho internacional del trabajo. Esto ha sucedido con la libertad de empresa y la libre competencia en confrontación con el derecho a la libertad sindical y las acciones de conflicto en defensa de los derechos de los trabajadores en el ámbito de otros países de la Unión ${ }^{47}$.

general del contrato y de la normativa internacional. En: www.iuslabor.org. Disponible en http://webcache.googleusercontent.com/ search?q=cache:dnCdLNRZ-JMJ:www.iuslabor.org/wp-content/plugins/download-monitor/download.php\%3Fid\%3D317+\&cd= $1 \& \mathrm{hl}=\mathrm{es} \& \mathrm{ct}=\mathrm{clnk} \& \mathrm{gl}=\mathrm{es} \& \mathrm{client}=$ firefox-b-d [consulta: 9 de abril de 2021].

${ }^{45}$ GUAMÁN HERNÁNDEZ, Adoración y NOGUERA FERNÁNDEZ, Albert, Derechos sociales, integración económica y medidas de austeridad. La UE contra el constitucionalismo social. Albacete, Bomarzo, 2014.

${ }^{46}$ El Gobierno de España ha comunicado recientemente que ha iniciado los trámites para la ratificación de la Carta Social Europea Revisada, incluyendo el sistema de reclamaciones colectivas, debiéndose cumplir todo el recorrido parlamentario para su publicación en el BOE y que se integre por fin en nuestro ordenamiento. Disponible en http://www.exteriores.gob.es/RepresentacionesPermanentes/ConsejodeEuropa/es/Noticias/Paginas/Articulos/20210204_NOT1.aspx . [ Consulta: 11 de abril de 2021]

${ }^{47}$ Se trata de los conocidos asuntos Viking, Laval y Ruffert que han sido analizados por diversos autores. Véase BAYLOS GRAU, Antonio, Derecho de huelga y medidas de conflicto. En: CASAS BAAMONDE, María Emilia y GIL ALBURQUERQUE, Román (dirs.), GARCÍA-PERROTE ESCARTÍN, Ignacio, GÓMEZ GARCÍA-BERNAL, Adriano y SEMPERE NAVARRO, Antonio (coords.). Derecho Social de la Unión Europea: aplicación por el Tribunal de Justicia, Madrid, Francis Lefebvre, 2018, pp. 1157-1179. CABRERA RODRÍGUEZ, José, Derechos fundamentales y libertades económicas en el ordenamiento comunitario: la jurisprudencia Viking y Laval. Revista Española de Derecho Constitucional, 99, 2013, pp. 371-428 y GUAMÁN HERNÁNDEZ, Adoración y NOGUERA FERNÁNDEZ, Albert. 2014, op. cit. 
Desde los ojos del Tribunal de Justicia de la Unión Europea la doctrina Melloni supuso la no aplicación del estándar más alto de los derechos cuando afecta al principio de primacía del Derecho comunitario lo que es criticable al ser un planteamiento contrario a una visión de protección integral de los derechos humanos ${ }^{48}$. Esta doctrina no debe llevar a que desde el plano interno prevalezca el Derecho comunitario sobre otros textos internacionales puesto que no existe jerarquía entre ambos $^{49}$. A esto se le agregan una serie de argumentos para justificar esta idea.

El Derecho de la UE y el Derecho internacional del trabajo emanan ambos de fuente supranacional. La integración de la Unión Europea se inserta a través de los artículos 93 y 94 de la Constitución española por la cesión de competencia de nuestro país en dicho proceso y tiene prevalencia en el derecho que procede de sus propias competencias comunitarias. Los textos del Derecho internacional del trabajo y la interpretación de sus órganos de control tienen prevalencia también desde el derecho interno por el artículo 96 CE. En este paralelismo, el Tribunal Constitucional en su declaración $1 / 2004^{50}$ se decantó porque el Derecho de la UE no se relaciona con el ordenamiento desde la supremacía que queda reservada para la Constitución. En definitiva la lógica del principio de primacía no deja de ser la misma que la del control de convencionalidad de la norma internacional puesto que ambas vienen a ser la expresión lógica de la Convención de Viena ${ }^{51}$ sobre la aplicación y respeto al contenido de los tratados. No obstante hay autores que mantienen que prima el principio de primacía por lo que para depurar el conflicto habría que plantear cuestión prejudicial ante el TJUE ${ }^{52}$.

Aquí se presenta el problema; la Constitución no ha articulado una solución expresa a la colisión entre el Derecho de la Unión Europea y el Derecho internacional del trabajo ${ }^{53}$. Cuando se produce el conflicto entre estas fuentes, las mismas ocupan el mismo rango en el sistema, puesto que no existe jerarquía entre las normas de la Unión Europea y las que emanan del Consejo de Euro$\mathrm{pa}^{54}$ o de la Organización Internacional del Trabajo. Es por esto que, en este caso, la resolución del conflicto ha de ser salvando el estándar más alto o la norma más favorable por una serie de razones. En primer lugar, por el carácter tuitivo que reviste al ordenamiento laboral, lo que llevaría a rechazar una lógica que implicaría reducir el estándar de protección para los trabajadores. En segundo lugar por la propia indivisibilidad de los derechos económicos, sociales y culturales y la protección multinivel de los mismos que proceden de las fuentes internacionales lo que hace que se opte por el enfoque más alto de los derechos. En tercer lugar y en relación con lo anterior, sería la plasmación de la clausula de mínimo mejorable o principio favor libertatis que se encuentra en el artículo 5 del Pacto Internacional de Derechos Civiles y Políticos, el artículo 5 del Pacto Internacional de Derechos Económicos Sociales y Culturales, el artículo 53 de la Carta de Derechos Fundamentales de la Unión Europea, el artículo 53 del Convenio Europeo de Derechos Humanos y el artículo 32 de la Carta Social Europea originaria. ${ }^{55}$ Todos estos artículos tienen una redacción muy similar en la búsqueda de la protección del estándar más alto, lo que debe llevar a que la resolución de un conflicto

\footnotetext{
${ }^{48}$ PRECIADO DOMENECH, Carlos Hugo. 2018, op. cit.

${ }^{49}$ SALCEDO BELTRÁN, Carmen, Reformas adoptadas frente a la crisis económica y Carta Social Europea. En: ALFONSO MELLADO, Carlos Luis, JIMENA QUESADA, Luis y SALCEDO BELTRÁN, Carmen, La jurisprudencia del Comité Europeo de Derechos Sociales frente a la crisis económica. Albacete, Bomarzo, 2014, pp. 97- 238.

${ }^{50}$ Declaración del Tribunal Constitucional 1/2004 de 13 de diciembre.

${ }^{51}$ JIMENA QUESADA, Luis, Jurisdicción nacional y control de convencionalidad. A propósito del diálogo judicial global y de la tutela multinivel de derechos. Cizur Menor (Navarra), Aranzadi, 2013, p. 25.

${ }^{52}$ FONDEVILA MARÓN, Manuel. 2019, op. cit.

${ }^{33}$ GÓMEZ FERNÁNDEZ, Itziar, Vínculos y relaciones entre el Derecho Internacional y el Derecho de la Unión Europea en el marco del ordenamiento espańol. Revista Aranzadi Doctrinal. 7, 2017, p. 211.

${ }^{54}$ SALCEDO BELTRÁN, C. 2014, op. cit.

${ }^{55}$ PRECIADO DOMÈNECH, Carlos Hugo, Teoría general de los derechos fundamentales en el contrato de trabajo. Cizur Menor (Navarra), Aranzadi, 2018, p. 275.
} 
que se produzca en nuestro ordenamiento jurídico la salida sea opuesta a la conocida en los asuntos Viking, Laval y Rüffert.

\section{El control de convencionalidad tras la reforma laboral de 2012}

En España dicho control ha tenido un recorrido limitado y su introducción es reciente. Se puede focalizar su incorporación efectiva como reacción a los efectos lesivos de la reforma laboral de 2012, fundamentalmente entre la colisión de la libertad de empresa y el derecho al trabajo en su dimensión de estabilidad en el empleo, ante la interpretación controvertida que de la misma ha hecho nuestro Tribunal Constitucional en sus sentencias 119/2014 y 8/2015. El Tribunal Constitucional en dichas resoluciones se ha situado en contra del estándar más alto europeo, lo que no ha impedido que ciertos órganos judiciales hayan seguido ejerciendo el control de convencionalidad ${ }^{56}$. El punto de conflicto principal se situó en torno a la figura del contrato de apoyo a los emprendedores aprobado con la Ley 3/2012 por su periodo de prueba de un ańo lo que conllevaba la extinción sin causa y la falta de indemnización en ese plazo. Ante esta regulación interna, que confrontaba con el artículo 4 del Convenio 158 de la Organización Internacional del Trabajo y con el artículo 4.4 de la Carta Social Europea, se sucedieron una serie de sentencias de los Juzgados de lo Social que ejercieron el control de convencionalidad ${ }^{57}$ y que se vieron revocadas por la doctrina de suplicación ${ }^{58}$. En este aspecto se ha precisado que el control de convencionalidad no vulnera el canon comunitario puesto que el Tribunal de Justicia de la Unión Europea se declaró incompetente para verificar la adecuación de dicho contrato con el Derecho comunitario en el asunto Nisttahuz Poclava C117/1459, sentencia de 5 de febrero de $2015^{60}$.

Los argumentos contrarios al control de convencionalidad reproducidos en la doctrina de suplicación se pueden resumir en los siguientes: el carácter meramente programático o no ejecutivo de la norma internacional, la consideración de no jurisprudencia de las resoluciones de los órganos de control o la no ratificación de la Carta Social Europea revisada y el peso de las resoluciones del Tribunal Constitucional avalando la constitucionalidad de la ley 3/2012.

Las perspectivas para el ejercicio del control de convencionalidad eran escasas a la vista de la doctrina de suplicación citada. Sin embargo, una serie de sentencias del Tribunal Superior de Justicia de Canarias ${ }^{61}$ rescatan el uso del control de convencionalidad aplicando el artículo 4.4 de la Carta Social Europea e inaplicando el artículo 4.3 de la Ley 3/2012, de 6 de julio, de medidas

${ }^{56}$ JIMENA QUESADA, Luis, El control de convencionalidad y los derechos sociales: nuevos desafíos en Espańa y en el ámbito comparado europeo (Francia, Italia y Portugal). Anuario Iberoamericano de Justicia Constitucional. 22, 2018, p. 31-58.

${ }^{57}$ Sentencia del Juzgado de lo Social núm. 2 de Barcelona 412/2013 de 19 de noviembre (procedimiento núm. 1037/2016), sentencia del Juzgado de lo Social núm. 3 de Barcelona 352/2014 de 5 de noviembre (procedimiento núm. 116/2014), sentencias del Juzgado de lo Social núm. 33 de Barcelona; la 339/2013 de 19 de noviembre (procedimiento núm. 398/2013), la de 9 de noviembre de 2015 (procedimiento núm. 162/2015) y la 472/2016 de 23 de diciembre (procedimiento núm. 1219/2014), Juzgado de lo Social núm. 1 de Tarragona 179/2014 de 2 de abril (procedimiento núm. 1043/2013), Juzgado de lo Social núm. 1 de Mataró 144/2014 de 29 de abril (procedimiento núm. 492/2013), Juzgado de lo Social núm. 1 de Toledo 667/2014 de 27 de noviembre (procedimiento núm. 536/2014), Juzgado de lo Social núm. 26 de Barcelona de 12 de marzo de 2018 (procedimiento núm. 1037/2016) y Juzgado de lo Social de Talavera de la Reina 152/2018 de 29 de junio (procedimiento núm. 109/2018).

${ }^{58}$ Se puede destacar la sentencia del TSJ de Cataluña 4090/2015 de 22 de junio (Ro 134/2015) que ha servido como una resolución muy reiterada por otros TSJ para negar el control de convencionalidad. Esta sentencia tiene un voto particular que firma el magistrado Carlos Hugo Preciado y al que se adhirieron 8 magistrados más, que aboga por el control de convencionalidad con una fundamentación solida y extensa.

${ }^{59}$ JIMENA QUESADA, Luis. 2018, op. cit.

${ }^{60}$ STJUE de 5 de febrero de 2015 (asunto C-117/14, Caso Nizttahuz Poclava y Ariza Toledano contra España)

${ }^{61}$ STSJ de las Islas Canarias con sede en Las Palmas, 30/2016 de 28 de enero (Ro 581/2015) y 73/2017 de 31 de enero ( $R^{\circ}$ $1300 / 2016)$ 
urgentes para la reforma del mercado laboral, interpretando que el efecto de la aplicación de la norma internacional en la extinción del contrato de apoyo a los emprendedores durante el periodo de prueba es el pago del preaviso ${ }^{62}$. Estas sentencias coinciden en que se trata de respetar el principio de jerarquía normativa en la prevalencia de la norma internacional donde se integran los informes del Comité Europeo de Derechos Sociales, no dudando del carácter self executing de dicho precepto de la Carta Social Europea. Para este Tribunal Superior de Justicia, la Carta Social Europea es un tratado en toda regla lo que implica que se respete su carácter supralegal y los informes y resoluciones del Comité Europeo de Derechos Sociales son jurisprudencia que ha de ser respetada por nuestros órganos judiciales internos. Como razona el tribunal es el propio artículo 29 de la Ley 25/2014, de 27 de noviembre, de Tratados y otros Acuerdos Internacionales, la que impone el respeto de las obligaciones de los tratados por todos los poderes públicos, órganos y organismos del Estado.

Aparcado el debate sobre el contrato de apoyo a los emprendedores al haber sido derogado, las siguientes sentencias muestran la incomodidad con nuestro actual estado de la legislación a raíz de la reforma laboral de 2012 con el modelo constitucional de relaciones laborales. En concreto se observa el planteamiento del control de convencionalidad respecto del despido por absentismo y el despido sin causa.

Comenzando por el despido objetivo por absentismo es trascendental la sentencia del Tribunal Superior de Justicia de Cataluña de 14 de enero de $2020^{63}$ que ejerce el control de convencionalidad de forma amplia ante un caso donde se discutía un despido por absentismo con anterioridad a que el Gobierno de España derogara el artículo 52.d) del Estatuto de los Trabajadores. La sentencia de instancia desestimó la demanda del trabajador, al entender ajustado a derecho el despido por bajas justificadas de carácter corto e intermitente. El Tribunal Superior de Justicia opera con la técnica de control basada en verificar si la redacción del artículo 52.d) del Estatuto de los Trabajadores era conforme con el Derecho internacional del trabajo. De la sentencia se desprende que el uso de la norma internacional se realiza de oficio, puesto que no consta que fuera invocada por la parte. En tal sentido, el tribunal entiende que el control de constitucionalidad ya lo ha acometido el Tribunal Constitucional y se trata de ejercer el control de legalidad conforme al artículo 6 de la Ley Orgánica del Poder Judicial. Un primer escollo que salva esta resolución es que el Tribunal Constitucional en la referida sentencia 118/2019 se pronuncia en el sentido que el artículo 52.d) del Estatuto de los Trabajadores es conforme con el artículo 6 del Convenio 158 de la Organización Internacional del Trabajo $^{64}$. Para el Tribunal Superior de Justicia de Catalunya esta es una consideración obiter dicta no encontrándose vinculado por la misma. Tras aplicar dicho filtro se determina que nuestra norma nacional recoge un nivel de protección inferior al estándar internacional en cuanto a la extinción del despido por IT/enfermedad, en materia de seguridad y salud de los trabajadores y en cuestión de género. En la lectura de esta extensa sentencia se percibe la visión de la interdependencia y la indivisibilidad de los derechos humanos para alcanzar estas conclusiones. En la combinación de la aplicación del canon hermenéutico y del control de convencionalidad, el tribunal entiende que la Carta Social Europea revisada aun no ratificada por España supone una indudable exégesis para la interpretación de nuestra normativa. En consecuencia el tribunal falla la improcedencia del despido por absentismo al contravenir la norma internacional.

Esta sentencia no ha estado exenta de crítica habiendo sido tildada de imprudente, fundamentalmente por dos motivos. El primero, por su interpretación del artículo 6.1 del Convenio 158 de la OIT abiertamente contraria a lo dicho por el Tribunal Constitucional en la referida sentencia

\footnotetext{
${ }^{62}$ Recuérdese que la norma supranacional europea establece el derecho a un plazo de preaviso razonable ante la terminación de la relación laboral y no la declaración de despido improcedente.

${ }^{63}$ STSJ de Cataluña 274/2020 de 14 de enero (Ro 5532/2019)

${ }^{64}$ Este artículo establece que la ausencia temporal del puesto de trabajo no será causa para terminar la relación laboral.
} 
118/2019 y el segundo, por su uso del artículo 24 de la Carta Social Europea revisada aun no ratificada por España. ${ }^{65}$

En cuanto a los supuestos de despido sin causa el Juzgado de lo Social 34 de Madrid se está pronunciando a favor del control de convencionalidad. La sentencia de 21 de febrero de $2020^{66}$ versa sobre un despido en el que consta acreditado que el mismo fue sin causa real. Es una resolución que utiliza la sustancial identidad de la regulación contenida en el Convenio 158 de la Organización Internacional del Trabajo con la Carta Social Europea Revisada para aplicar las resoluciones del Comité Europeo de Derechos Sociales en asuntos sobre Finlandia e Italia ${ }^{67}$ cuyo nexo común es el derecho de los trabajadores a gozar de una indemnización apropiada cuando se produzca un despido sin causa/motivo válido y activar una compensación adecuada en reparación de los despedidos. En el razonamiento se concluye que nuestra regulación del despido es contraria al marco internacional. En consecuencia dicta la nulidad del despido y utiliza la reparación que comprende el artículo 10 del Convenio 158 de la Organización Internacional del Trabajo para asignar una indemnización como disuasoria a la conducta empresarial y por ello añadida a la tasada en el artículo 56 del Estatuto de los Trabajadores. En esta resolución llama la atención que se argumente que el Convenio 158 de la Organización Internacional del Trabajo no tiene interprete auténtico para acudir a las resoluciones del Comité Europeo de Derechos Sociales, sobre un texto no ratificado por España aun, cuando el Comité de Expertos en Aplicación de Convenios y Recomendaciones emite informes periódicos sobre el nivel del cumplimiento del convenio conforme a la legislación nacional de los Estados. Por el juzgador no solo se dicta la nulidad del despido en este caso sino que lo hace por la nulidad de nuestra normativa de despido entre otras razones por su falta de acomodación a la norma internacional.

\section{El control de convencionalidad con la Covid-19}

Uno de los elementos clave para que funcione este control es el diálogo judicial, como debate entre órganos de distintos ámbitos. En este sentido, se detecta que se va avanzando en este campo, puesto que las sentencias producidas en este periodo son más ricas en cuanto a su conocimiento de la norma internacional y las resoluciones de otros órganos, entablándose un debate más elevado de la cuestión. En este periodo y retomando la senda de las sentencias analizadas anteriormente se centra el debate en los despidos sin causa, los despidos por las causas relacionadas con la Covid-19 y la posibilidad de la impugnación del despido individual en el marco de un despido colectivo con acuerdo.

Comenzando por la sentencia del Juzgado de lo Social 26 de Barcelona de 31 de julio de $2020^{68}$, estudia un asunto en el que se ha despedido a un trabajador por causas organizativas en el escenario de la Covid-19. En primer lugar, el juzgador se pronuncia sobre el alcance del artículo 2 del Real Decreto-Ley 9/2020, de 27 de marzo, por el que se adoptan medidas complementarias, en el ámbito laboral, para paliar los efectos derivados del Covid-19. El criterio de la sentencia en este aspecto es que la redacción de ese precepto no implica la prohibición del despido, como

${ }^{65}$ ALONSO GARCÍA, Ricardo, El control de convencionalidad: cinco interrogantes. Revista Española de Derecho Constitucional. 119, 2020, pp. 13-51.

${ }^{66}$ Sentencia del Juzgado de lo Social núm. 34 de Madrid 71/2020 de 21 de febrero de 2020 (procedimiento núm. 843/2019)

${ }^{67}$ Asunto Finnish Society vs. Finlandia. Reclamación no 106/2014. Disponible en http://hudoc.esc.coe.int/eng/?i=cc-106-2014-dadmissandmerits-en [consulta: 9 de abril de 2021].

Asunto CGIL vs. Italia. Reclamación no 158/2017. Disponible en http://hudoc.esc.coe.int/eng?i=cc-158-2017-dmerits-fr

${ }^{68}$ SJS 26 de Barcelona 170/2020 de 31 de julio 
han defendido sectores de la doctrina ${ }^{69}$ sino que las causas de fuerza mayor o causas ETOP por el Covid-19 que dan cobertura a los ERTES no serán justificativas de la extinción, siendo la consecuencia la improcedencia y no la nulidad de la extinción. En relación con la causalidad del despido el juzgador acude a la doctrina del despido improcedente por fraudulento que emana del Tribunal Supremo ${ }^{70}$. Lo novedoso de esta sentencia es que aplica el control de convencionalidad sobre las consecuencias del despido improcedente que derivan del artículo 56 del Estatuto de los Trabajadores. A diferencia de la sentencia recién citada del Juzgado de lo Social 34 de Madrid no se cuestiona la validez del régimen legal del despido sino las consecuencias de este en la reparación al trabajador. Para el juez, el Convenio 158 de la Organización Internacional del Trabajo impone la causalidad del despido y, en el caso que los efectos del abono de la indemnización no supongan un esfuerzo disuasorio para la empresa acude al artículo 10 del Convenio 158, que permite al órgano judicial ordenar la imposición de una indemnización adecuada cuando llegue a la conclusión que la legislación interna no permite la anulación de la terminación injustificada de la relación laboral. En utilización de la norma internacional el juez, en atención a las circunstancias concurrentes, establece una indemnización adicional conforme al Convenio 158 de la Organización Internacional del Trabajo y a lo dicho por el Comité Europeo de Derechos Sociales en las reclamaciones colectivas presentadas contra Italia y Finlandia ya referidas, para resarcir al trabajador con una indemnización de $60.000 €$ adicionales equivalentes a 9 meses de salario. Esta sentencia consciente de la transcendencia del cumplimiento del canon internacional dio un trámite adicional de alegaciones a las partes sobre este aspecto.

Incluso las resoluciones que no se decantan por la prevalencia de la norma internacional están arrojando un debate sobre nuestro modelo de causalidad en relación con los estándares de fuente internacional. La sentencia 3550/2020 de la Sala de lo Social del Tribunal Superior de Justicia de Catalunya $^{71}$ es un buen ejemplo de ello. En este caso, la mayoría de los magistrados no aplican el control de convencionalidad. Es un despido sin causa en el que la sentencia de instancia declaró la improcedencia de este. La parte actora recurrió, entre otros motivos, alegando la nulidad de la extinción en base al Convenio 158 de la Organización Internacional del Trabajo. La sentencia de suplicación que cuenta con un voto particular que analizo más adelante, pese a que rechaza la nulidad a la luz de la norma internacional, no niega que hay que contrastar la norma internacional con la interna para, en caso de que se observe contradicción, inaplique la norma nacional.

El sentir mayoritario de la Sala, al margen del razonamiento basado en nuestra regulación interna $^{72}$, asume la posibilidad del control de convencionalidad y ejerce el diálogo de la norma internacional con la interna. Esto supone un indudable avance puesto que, aunque se rechaza la existencia de contradicción, no se excluye una hipotética aplicación del control. Para los magistrados que motivan la sentencia entienden que ni el Convenio 158 de la Organización Internacional del Trabajo, ni la Carta Social Europea ni la Carta de Derechos Fundamentales de la Unión Europea ni el Convenio Europeo de Derechos Humanos ${ }^{73}$ imponen la nulidad por la falta de causalidad

${ }^{69}$ BAYLOS GRAU, Antonio, 2020. La prórroga del estado de alarma y medidas laborales adicionales de garantía del empleo en la crisis del Covid-19. En: https://baylos.blogspot.com .Disponible en https://baylos.blogspot.com/2020/03/la-prorroga-del-estado-dealarma-y.html [Consulta: 9 de abril de 2021].

${ }^{70}$ STS de 29 de septiembre de 2014 (Ro 3248/2013)

${ }^{71}$ STSJ de Cataluña, de 21 de julio (Ro 4708/2019)

${ }^{72}$ Basado en la causalidad de nuestro ordenamiento, la nulidad queda reservada para los supuestos de violación de derechos fundamentales y el despido sin causa, incluso fraudulento, lleva como consecuencia la declaración de la improcedencia del despido y no la nulidad de este.

${ }^{73}$ El TSJ analiza la STEDH de 10 de julio de 2012 (Núm. no. 19554/11, caso KMC contra Hungría) en el que se denunciaba la lesión del derecho a la defensa ante una legislación que posibilitaba el despido sin causa y donde la carga de la prueba para acreditar que el despido había sido injusto era del trabajador, lo que motivó que el accionante no demandara ante las nulas opciones para el éxito su reclamación. El TEDH en este caso entendió que esta regulación vulneraba el artículo 6.1 del CEDH que garantiza el derecho a un jui- 
del despido. Es más sobre el Convenio 158 y la Carta Social Europea, interpretan que las mismas plantean la posibilidad de la indemnización adecuada cuando se despida sin causa; es decir, que se acomodan a nuestra legislación en este aspecto sobre la improcedencia por la falta de causa en la extinción. En definitiva, defienden que para que se declare la nulidad en este tipo de despidos fraudulentos o sin causa se debe emprender una reforma legislativa que pueda dar acomodo a tal previsión.

Sin embargo, existe un voto particular del magistrado Jordi Agustí Maragall al que se adhieren ocho magistrados más, que hace un planteamiento muy solvente sobre el conocimiento de la norma internacional e incluso llama a actualizar la jurisprudencia sobre la institución del despido conforme a la voluntad del legislador tras la reforma de 2012 de reforzar la causalidad con la eliminación del despido exprés, cuestión que no se ha replanteado. El enfoque del voto particular parte de diferenciar dos posturas desde la óptica constitucional: la invocación de la causa del despido como meramente formal o la causalidad como elemento de dimensión constitucional, posición esta última en la que se sitúan.

Desde la norma internacional, la posición minoritaria de la sentencia entiende que el Convenio 158 de la Organización Internacional del Trabajo impone la existencia de la causa real, el derecho a la defensa previo al despido disciplinario, el control de la concurrencia de la causa y justificación por órgano judicial neutral y la reparación más adecuada ante el despido injustificado se impide cuando la causa que expresa la carta de despido no es real. En consecuencia, conecta estas garantías con el derecho a la tutela judicial efectiva. En esa indefensión que se le produce a un trabajador que se encuentra ante una carta de despido que consigna una causa ficticia, se realiza una lectura distinta a la posición mayoritaria del fallo en relación con la Sentencia del Tribunal Europeo de Derechos Humanos de 10 de julio de 2012 (KMC c/Hungría), en su interpretación del artículo 6.1 del Convenio Europeo de Derechos Humanos, como que la falta de explicitación de la causa de despido vulnera la tutela judicial efectiva. Reforzando el carácter esencial de la causalidad en el despido acuden al artículo 24 de la Carta Social Europea, a las propias resoluciones del Comité Europeo de Derechos Sociales y al artículo 30 de la Carta de Derechos Fundamentales de la Unión Europea. Para el voto particular la causalidad no puede ser un requisito meramente formal por lo dispuesto en los mandatos internacionales y su incumplimiento no cabe ser sancionado únicamente con la improcedencia del despido. En definitiva, el voto particular lamenta que no se haya producido una evolución jurisprudencial para expulsar del ordenamiento el despido sin causa o causa ficticia cuando la propia voluntad del legislador en la reforma de 2012 fue reforzar la causalidad, por los mandatos del Convenio 158 de la Organización Internacional del Trabajo y la reciente jurisprudencia del Tribunal Supremo en materia de fraude de ley en el despido objetivo.

Otro paso en firme a favor del control de convencionalidad viene de la sentencia 412/2020 de la Sala de lo Social del Tribunal Superior de Justicia de Baleares ${ }^{74}$. En este asunto se discutía por dos trabajadores de forma individual las causas que derivaban de un despido colectivo terminado con acuerdo con los representantes de los trabajadores pero sin posterior impugnación colectiva. Cabe matizar que la autoridad laboral impugnó judicialmente exclusivamente por el fraude de ley en el desarrollo del periodo de consultas, lo que fue desestimado en otro procedimiento al margen. La sentencia de instancia desestimó la demanda amparándose en la sentencia del Tribunal Supremo 699/2018 75 . En esta resolución el Tribunal Supremo, tras una larga fundamentación que se transporta desde la regulación del artículo 124.13 de la Ley Reguladora de la Jurisdicción Social hasta la exposición de motivos de la Ley 3/2012 que busca reducir la litigiosidad en el orden social; viene a

\footnotetext{
cio justo ante un tribunal. Para la mayoría de la Sala esta sentencia no es aplicable a nuestro ordenamiento puesto que el mismo es causal y su ausencia conlleva la calificación del despido como improcedente, contenido regulatorio que no concurre en la legislación húngara.

${ }^{74}$ STSJ de Islas Baleares, de 18 de noviembre (Ro 179/2020).

${ }^{75}$ STS de 2 de julio de 2018 (Ro 2250/2016, Sala de lo Social)
} 
defender que la impugnación individual cuando el Despido Colectivo termina en acuerdo solo cabe cuando concurre fraude, dolo, coacción o abuso de derecho.

Sin embargo, el Tribunal Superior de Justicia de Baleares realiza el control desde la perspectiva internacional. En tal técnica, en primer lugar rechaza que el Derecho de la Unión Europea imponga la posibilidad de cuestionar la existencia de la causa desde el plano individual en estos supuestos. Para la Sala la exigencia de la causa de nuestra regulación interna es una mejora en relación con el Derecho comunitario. A continuación, la Sala acude al Convenio 158 de la Organización Internacional del Trabajo para, en primer lugar, precisar que el Tribunal Supremo en la referida sentencia no abordó la cuestión desde esta norma internacional. El criterio de la Sala es discrepante con la interpretación del Alto Tribunal del artículo 124.13 LRJS puesto que lo dispuesto en el Convenio 158 de la Organización Internacional del Trabajo impide esa lectura restrictiva. Para la Sala no cabe establecer una presunción de la causa iure et de iure sino que, en todo caso, debería ser una presunción iurus tantum que posibilite el control de la causa por el órgano neutral, siendo esta la interpretación que casa con el orden internacional.

\section{Conclusiones}

El debate sobre el control de convencionalidad sigue más vivo que nunca. Cada vez se detecta una mayor familiaridad y un mayor nivel de motivación de los órganos judiciales a la hora de justificar sus decisiones desde el canon internacional. El avance es innegable puesto que el debate ya ha sido recogido por el TSJ de Canarias, el TSJ de Catalunya y el TSJ de Baleares.

Se echa en falta en la cuestión que la Sala Cuarta del Tribunal Supremo acoja el debate sobre el control de convencionalidad de forma expresa. La Sala Tercera del Tribunal Supremo es un buen ejemplo, puesto que en su sentencia de 17 de julio de $2018^{76}$ fue contundente en la existencia del control de convencionalidad y del debido cumplimiento a los informes del CEDAW como comité de Naciones Unidas que vincula a España. No se obvia que existen un buen número de resoluciones de la Sala Cuarta que no dudan en que la norma internacional del trabajo se integra en nuestro ordenamiento a través del canon hermenéutico del artículo 10.2 de la Constitución espańola pero se hace necesario acudir al control de convencionalidad para asegurar el cumplimiento de la norma internacional.

El marco del debate es más amplio que desde el control de convencionalidad en sentido estricto. El voto particular de la sentencia del Tribunal Superior de Justicia de Catalunya de 21 de julio de 2020 viene a conectar la necesaria causalidad como expresión del derecho a la tutela judicial efectiva a la luz de las normas internacionales. Se trata de reforzar la causalidad del despido en nuestra legislación alimentada por la fuente internacional. En este sentido hay que reivindicar este mecanismo junto al canon hermenéutico que vigoriza la Constitución y el sistema de fuentes que lleva aparejado ${ }^{77}$. Aun siendo conscientes de la necesidad de un uso moderado del control de convencionalidad que compete al juez ordinario en la aplicación de la ley aplicable, es un mecanismo de encaje constitucional. Se atisba que crece el debate sobre si la institución del despido y las garantías de defensa y protección para los trabajadores se ajustan al canon internacional tras haberse asentado una regulación derivada de la reforma laboral de 2012 que al eliminar los salarios de tramitación desincentiva en gran medida a los trabajadores la defensa de sus derechos ante la jurisdicción social.

El anuncio de la ratificación de la Carta Social Europea Revisada por España es una buena noticia. En primer lugar, porque supone asumir más derechos de los que nuestro país estaba com-

\footnotetext{
${ }^{76}$ STS de 17 de julio de 2018 (Ro 1002/2017, Sala de lo Contencioso-Administrativo)

${ }^{77} \mathrm{Al}$ respecto, JIMENA QUESADA, Luis. 2013, op. cit., p. 28.
} 
prometido. En segundo lugar, porque la ratificación del protocolo de reclamaciones colectivas permite su acceso por parte de las organizaciones sindicales al Comité Europeo de Derechos Sociales para denunciar los casos concretos que puedan ser vulneradores de la Carta ${ }^{78}$.

Son comprensibles y fundados los recelos y los problemas de encaje ante el control de convencionalidad. Sin embargo, es pertinente resaltar que el Derecho comunitario goza de una presunción de conformidad con el Convenio Europeo de Derechos Humanos ${ }^{79}$ y a su vez el otro gran bloque de normativa internacional, el que procede la Organización Internacional del Trabajo, goza de gran respeto en el marco europeo y nacional. Es por esto que, seria interesante abordar la interpretación de dichas fuentes de forma convergente y armonizadora y no desde la contraposición permanente que puede hacer pensar a una relectura de nuestro ordenamiento laboral en gran parte de sus contenidos. En este sentido, es criticable que España no haya ratificado el Protocolo 16 ante el TEDH para en este aspecto poder plantear cuestiones prejudiciales ante este marco, lo que sin duda ayudaría al diálogo y la coordinación entre órganos judiciales.

Para terminar sigue siendo necesario acometer un plan de formación internacionalista desde el plano de los derechos humanos donde la doctrina científica y judicial sigue jugando un papel esencial. No se debe olvidar que el Comité de Derechos Económicos, Sociales y Culturales exigió en sus conclusiones, ya referidas, del año 2018 que se debe acometer urgentemente dicha formación sobre el conocimiento del Pacto en los aplicadores de este en la vía interna y el respeto a los derechos humanos en las empresas. En definitiva un conocimiento mayor de los operadores jurídicos y de la sociedad civil en general en materia de derechos humanos sentará las bases para una mayor armonización de los estándares de derechos, desde el escenario de protección multinivel de los mismos.

\footnotetext{
${ }^{78}$ Se trata de un procedimiento complejo y dilatado en el tiempo por lo que es conveniente ser prudentes en este punto, véase BAYLOS GRAU, Antonio, 2020. Sobre la ratificación de la Carta Social Europea revisada y su protocolo adicional. En https://baylos.blogspot.com . Disponible en https://baylos.blogspot.com/2020/11/sobre-la-ratificacion-de-la-carta.html [consulta: 9 de abril de 2021].

${ }^{79}$ ONDEVILA MARÓN, Manuel. 2019, op. cit.
} 